\title{
Activation of phenylpropanoid pathway in legume plants exposed to heavy metals. Part ll. Profiling of isoflavonoids and their glycoconjugates induced in roots of lupine (Lupinus luteus) seedlings treated with cadmium and lead
}

\author{
Sylwia Pawlak-Sprada1 ${ }^{1}$ Maciej Stobiecki² and Joanna Deckert ${ }^{1 凶}$ \\ 1Department of Plant Ecophysiology, Institute of Experimental Biology, Faculty of Biology Adam Mickiewicz University, Poznań, Poland; \\ Institute of Bioorganic Chemistry, Polish Academy of Sciences, Poznań, Poland
}

\begin{abstract}
We examined changes in profiles of isoflavonoids in roots of lupine (Lupinus luteus L. cv. Juno) seedlings in response to treatment with two heavy metals: cadmium (at $10 \mathrm{mg} / \mathrm{l}$ ) and lead (at $150 \mathrm{mg} / \mathrm{l}$ ). Overall, 21 flavonoid conjugates were identified in root extracts, some of them with up to six positional isomers. The total amount of all isoflavonoids increased by about $15 \%$ in cadmiumtreated plants and by $46 \%$ in lead-treated ones. Heavy metals markedly increased the content of two compounds: 2'-hydroxygenistein glucoside and 2'-hydroxygenistein 7-O-glucoside malonylated. Possible functions of the identified isoflavonoids in yellow lupine exposed to heavy metal stress are discussed.
\end{abstract}

Keywords: cadmium, isoflavonoid, lead, lupine, phenylpropanoid pathway

Received: 05 November, 2010; revised: 24 January, 2011; accepted: 08 March, 2011; available on-line: 19 April, 2011

\section{INTRODUCTION}

Heavy metals, such as cadmium and lead, are environmental pollutants, that affect various physiological processes in plants. The plant response to different abiotic and biotic stress factors is frequently correlated with an enhancement of phenylalanine ammonia-lyase (PAL; EC 4.3.1.5) activity, a key enzyme of the phenylpropanoid pathway. Several products of this pathway such as coumarins, lignin, flavones, isoflavones, flavonols and anthocyanins are involved in plant defense against various environmental factors (Dixon \& Paiva, 1995; Dixon et al., 2002; Winkel-Shirley, 2002; Jung et al., 2003; Treutter, 2005; Taiz \& Zeiger, 2006). Heavy metals activate the phenylpropanoid pathway and increase lignin synthesis in many plant species (Diaz et al., 2001; Jouili \& Ferjani, 2003; Lin et al., 2005; Yang et al., 2007; Kovacik \& Klejdus, 2008). However, not all plants respond to heavy metals in the same manner. Recently we have found that while the treatment of soybean (Glycine max) seedlings with cadmium $\left(\mathrm{Cd}^{2+}\right)$ or lead $\left(\mathrm{Pb}^{2+}\right)$ trigged an increase of PAL mRNA level, PAL activity and lignin content, the same treatment of yellow lupine (Lupinus luteus) seedlings stimulated of PAL activity but decreased the lignin content (Pawlak-Sprada et al., 2011). This suggest that the activation of phenylpropanoid pathway by $\mathrm{Cd}^{2+}$ or $\mathrm{Pb}^{2+}$ in lupine roots enhanced the synthesis of secondary metabolites other than lignin.
The aim of this study was to determine whether $\mathrm{Cd}^{2+}$ and $\mathrm{Pb}^{2+}$ affect the profile of flavonoids in the root of yellow lupine seedlings. The flavonoid compounds were analyzed by liquid chromatography-mass spectrometry (LC/ESI/MS/MS) (Bednarek et al., 2003; Kachlicki et al., 2005; 2008; Muth et al., 2008) that allowed differentiation and quantification of flavonoids (flavones and isoflavones) and their glycosides.

\section{MATERIALS AND METHODS}

Plant material. Seeds of yellow lupine (Lupinus luteus L. cv. Juno) were surface sterilized with $75 \%$ ethanol for $5 \mathrm{~min}$, followed by $1 \%$ sodium hypochloride for 10 min, washed in water and germinated for $48 \mathrm{~h}$ on watermoistened filter paper in Petri dishes. The seedlings were then transferred to dishes containing $5 \mathrm{ml}$ of either distilled water (control), aqueous solution of $\mathrm{CdCl}_{2}$ containing $10 \mathrm{mg} / 1$ of $\mathrm{Cd}^{2+}$ (which corresponds to $89 \mu \mathrm{M} \mathrm{CdCl}$ ) or aqueous solution of $\mathrm{Pb}\left(\mathrm{NO}_{3}\right)_{2}$ containing $150 \mathrm{mg} / 1$ of $\mathrm{Pb}^{2+}$ (which corresponds to $\left.724 \mu \mathrm{M} \mathrm{Pb}\left(\mathrm{NO}_{3}\right)_{2}\right)$. The seedlings were incubated in the dark at $22^{\circ} \mathrm{C}$ for $48 \mathrm{~h}$.

Analysis of isoflavonoids. Isolation of phenolic compounds from plant tissue. Prior to LC profiling of isoflavone glucosides, samples of frozen plant material (0.1 g fresh weight of roots) were homogenized in $80 \%$ methanol $(10 \mathrm{ml} / \mathrm{g}$ fresh weight of tissue) in a mortar with pestle and then sonicated for $30 \mathrm{~min}$. The suspension was filtered through a Buchner funnel and concentrated under vacuum at $40^{\circ} \mathrm{C}$. The samples were purified and concentrated by solid phase extraction (SPE) on cartridges containing a cation exchanger and RP C-18 silica gel (Alltech, Carnforth, England) used in tandem, according to the method of Stobiecki et al. (1997).

Identification and quantification of isoflavonoids and their glycoconjugates. Identification was done on the basis of high resolution collision induced dissociation (CID) MS/MS spectra $(\mathrm{m} / \mathrm{z}$. values registered with accuracy better than $5 \mathrm{ppm}$ ) and their retention times registered for consecutive compounds analyzed with a liquid chromatography tandem mass

e-mail address: Joanna.Deckert@amu.edu.pl

Abbreviations: CID, collision induced dissociation; LC/ESI/MS/MS liquid chromatography electrospray ionisation tandem mass spectrometry; LC, liquid chromatography; $m / z$, mass-to-charge ratio; MS, mass spectrometry; MS/MS, tandem mass spectrometry; PAL, phenylalanine ammonia-lyase 
spectrometry (LC/ESI/MS/MS), consisted of LC system model 1200 SL containing binary pump SL, diode array detector G1315C Starlight and automatic injector G1367C SL WP (Agilent Technologies, Waldbronn, Germany) connected to a micrOTOF-Q spectrometer (Bruker, Bremen, Germany). The analyses were carried out using a Zorbax Eclipse XDB-C18 column $(2.1 \mathrm{~mm} \times 100 \mathrm{~mm}$, grain diameter $1.8 \mu \mathrm{m})$ from Agilent. Chromatographic runs were performed at a 0.5 $\mathrm{ml} / \mathrm{min}$ flow rate using mixtures of two solvents: A (99.5\% $\mathrm{H}_{2} \mathrm{O}, 0.5 \%$ formic acid, v/v) and $\mathrm{B}(99.5 \%$ acetonitrile, $0.5 \%$ formic acid, $\mathrm{v} / \mathrm{v}$ ) with a split of the column effluent $3: 2$ so $0.2 \mathrm{ml} / \mathrm{min}$ was delivered to the ESI ion source. The elution steps were as follows: 0-8 min linear gradient from 5 to $30 \%$ of $\mathrm{B}, 8-10$ min linear gradient to $95 \% \mathrm{~B}, 10-12 \mathrm{~min}$ isocratic at $95 \%$ B. After return to the initial conditions column equilibration was achieved after $3 \mathrm{~min}$.

The micrOTOF-Q mass spectrometer was run with ESI at $\pm 4.5 \mathrm{kV}$, nebulisation with nitrogen at 1.6 bar and dry gas flow of $8.0 \mathrm{~L} / \mathrm{min}$ at $220^{\circ} \mathrm{C}$. The system was calibrated externally using a calibration mixture containing sodium formate clusters. Additional internal calibration was performed for every run by injection of the calibration mixture using the divert valve during the LC separation. All calculations were done with the HPC quadratic algorithm. Such a calibration gave at least 5 p.p.m. accuracy of $\mathrm{m} / \mathrm{z}$ value annotation. MS/MS spectra were acquired with the frequency of one scan per second for ions chosen on the basis of preliminary experiments. The collision energy depended on the molecular masses of the compounds and was set between 10 and $25 \mathrm{eV}$. The instrument operated at a resolution higher than 10000 (FWHM, full width at half maximum) under the program micrOTOF Control version 2.3 and data was analysed using the DataAnalysis version 4 package delivered by Bruker.

Identification of 21 isoflavone glycoconjugates was done on the basis of high resolution MS and CID MS/ MS spectra.

Quantification of identified compounds was performed on the basis of peak areas registered in single ion chromatograms of protonated molecules $[\mathrm{M}+\mathrm{H}]^{+}$ of consecutive compounds eluted from the LC column. Peak areas were compared with a calibration curve prepared with genistein 7-O- $\beta$-D-glucoside at concentrations between $50 \mathrm{ng} / \mathrm{ml}$ and $2 \mu \mathrm{g} / \mathrm{ml}$. The concentrations of all recognized isoflavonoid glycoconjugates were expressed as equivalents of genistein 7-O- $\beta$-D-glucoside.

Statistics. All results are presented as means \pm S.D. (standard deviation) obtained from six independent replicates derived from tree independent biological experiments.

\section{RESULTS AND DISCUSSION}

Methods based on liquid chromatography mass spectrometry that allow the identification and quantification

Table 1. Compounds identified in Lupinus luteus roots treated with heavy metals

\begin{tabular}{|c|c|c|c|c|}
\hline Peak \# & $\begin{array}{l}\mathrm{Rt} \\
(\mathrm{min})\end{array}$ & Compound identified & $\begin{array}{l}{[\mathrm{M}+\mathrm{H}]^{+}} \\
\mathrm{m} / \mathrm{z} \\
\text { (calculated) }^{\mathrm{b}}\end{array}$ & $\begin{array}{l}{[\mathrm{M}+\mathrm{H}]^{+}} \\
\mathrm{m} / \mathrm{z} \\
\text { (registered)b }^{\mathrm{b}}\end{array}$ \\
\hline 1 & 1.4 & Genistein 8-C-7-O-diglucoside & 595.1663 & 595.1667 \\
\hline 2 & 1.9 & Genistein 4',7-O-diglucoside & 595.1663 & 595.1671 \\
\hline 3 & 3.2 & Genistein 4',7-O-diglucoside malonylated la & 681.1667 & 681.1693 \\
\hline 4 & 3.4 & 2'-Hydroxygenistein glucoside & 449.1084 & 449.1089 \\
\hline 5 & 3.5 & Genistein 4',7-O-diglucoside malonylated Ila & 681.1667 & 681.1672 \\
\hline 6 & 3.8 & Genistein 8-C-glucoside & 433.1135 & 433.1135 \\
\hline 7 & 3.8 & Genistein 4',7-O-diglucoside malonylated IIla & 681.1667 & 681.1669 \\
\hline 8 & 4.0 & Genistein 4',7-O-diglucoside malonylated IVa & 681.1667 & 681.1682 \\
\hline 9 & 4.0 & Genistein 8-C-glucoside malonylated la & 519.1139 & 519.1147 \\
\hline 10 & 4.3 & $2^{\prime}$-Hydroxygenistein 7-O-glucoside malonylated la & 535.1088 & 535.1085 \\
\hline 11 & 4.3 & Genistein 4',7-O-diglucoside dimalonylated la & 767.1671 & 767.1683 \\
\hline 12 & 4.5 & Genistein 8-C-glucoside malonylated Ila & 519.1139 & 519.1151 \\
\hline 13 & 4.5 & Genistein 7-O-glucoside & 433.1135 & 433.1131 \\
\hline 14 & 4.6 & 2'-Hydroxygenistein 7-O-glucoside malonylated Ila & 535.1088 & 535.1078 \\
\hline 15 & 4.7 & Genistein 4',7-O-diglucoside dimalonylated IIa & 767.1671 & 767.1665 \\
\hline 16 & 4.8 & 2'-Hydroxygenistein 7-O-glucoside malonylated IIIa & 535.1088 & 535.1079 \\
\hline 17 & 5.0 & Genistein $4^{\prime}$ or 7-O-glucoside malonylated la & 519.1139 & 519.1132 \\
\hline 18 & 5.2 & Genistein 4'-O-glucoside & 433.1135 & 433.1130 \\
\hline 19 & 5.5 & Genistein $4^{\prime}$ or $7-0-$ glucoside malonylated Ila & 519.1139 & 519.1138 \\
\hline 20 & 5.7 & Genistein $4^{\prime}$ or $7-0$-glucoside malonylated III & 519.1139 & 519.1137 \\
\hline 21 & 6.2 & 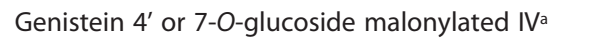 & 519.1139 & 519.1134 \\
\hline
\end{tabular}

$[\mathrm{M}+\mathrm{H}]^{+}$, protonated molecule. aSubstitution of glucose moiety on an aglycone and position of sugar malonylation position is not defined on the basis of registered mass spectra. bMass to charge ratio $(\mathrm{m} / \mathrm{z})$ is calculated to the fourth decimal point for defined elemental composition, these values correspond within 5 p.p.m. to exact mass of $[\mathrm{M}+\mathrm{H}]^{+}$ions registered for respective compounds (1-21). 


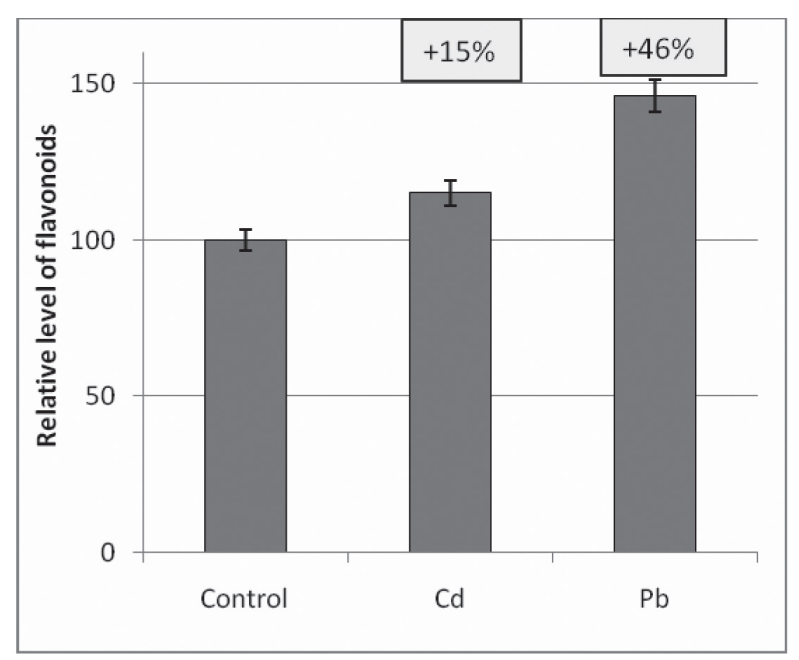

Figure 1. Total flavonoids in roots of $L$. luteus under heavy metal stress

Values are means \pm S.D. of three independent experiments.

of various flavonoids derived from plant material have been described (Fossen \& Andersen, 2006; Stobiecki \& Kachlicki, 2006). In the present study 21 different compounds were identified in yellow lupine root extracts (Table 1). In the case of genistein and 2'-hydroxygenistein glycoconjugates, especially malonylated glycosides, various positional isomers were found. Ultrahigh pressure liquid chromatography has earlier been shown to resolve isomers of malonylated isoflavonoid glycosides from Lupinus angustifolius plants (Muth et al., 2008). However, in the present study, application of ultra performance liquid chromatography (UPLC) permitted to separate the isomers, but it was not possible to define the position of malonylation on the basis of registered mass spectra. All identified compounds are isoflavone monoor diglucosides and 15 of them are isomers of the isoflavone glycoconjugates malonylated at different positions of the sugar moiety. A similar composition of isoflavonoids has been detected in roots of two other lupine species: L. albus and L. angustifolius (Bednarek et al., 2003; Kachlicki et al., 2005) and most of them were also identified in leaves of L. angustifolius (Bednarek et al., 2003; Muth et al., 2009). The most abundant compounds in yellow lupine roots of control plants are: genistein 4'- or 7-O-glucoside and 8-C-glucoside $(\mathbf{6}, \mathbf{1 3}, \mathbf{1 8})$ (Fig. 3a-c) and some of their malonylated derivatives $(17,19,20$, 21) (Fig. 3d). The qualitative composition of isoflavone glycoconjugates derived from control, metal-untreated roots, was the same as that of isoflavonoids isolated from lupine roots treated with cadmium $\left(\mathrm{Cd}^{2+}\right)$ or lead $\left(\mathrm{Pb}^{2+}\right)$. The total amount of the isoflavonoids increased by about $15 \%$ in $\mathrm{Cd}^{2+}$-treated plants and by about $46 \%$ in $\mathrm{Pb}^{2+}$-treated plants (Fig. 1). Most of the identified isoflavone glycoconjugates showed some increase upon the treatment (Figs. 2-4). The largest increase was observed for two compounds: 2'-hydroxygenistein glucoside (4) and its malonylated isomers $(\mathbf{1 0}, \mathbf{1 4}, \mathbf{1 6})$ (Fig. 2a and 2b). The amount of 2'-hydroxygenistein glucoside (4) in roots of $\mathrm{Cd}^{2+}$-treated seedlings was 36 times higher and in $\mathrm{Pb}^{2+}$-treated seedlings 219 times higher than in the control plants (Fig. 2a). Also the level of malonylated derivatives of 2'-hydroxygenistein 7-O-glucoside increased substantially upon treatment with $\mathrm{Cd}^{2+}$ or $\mathrm{Pb}^{2+}: 21$-fold and 85-fold, respectively (Fig. 2b). Smaller increases were found for genistein diglucosides (Fig. 4a) and their malonylated (Fig. 4b) and dimalonylated forms (Fig. 4c) and smaller still for genistein monoglucosides (Fig. 3a-c) and theirs malonylated forms (Fig. 3d). The only compound whose level was decreased in the presence of either metal was genistein 4'-O-glucoside (Fig. 3c). These data suggest that two types of genistein modifications are im-

a)

b)
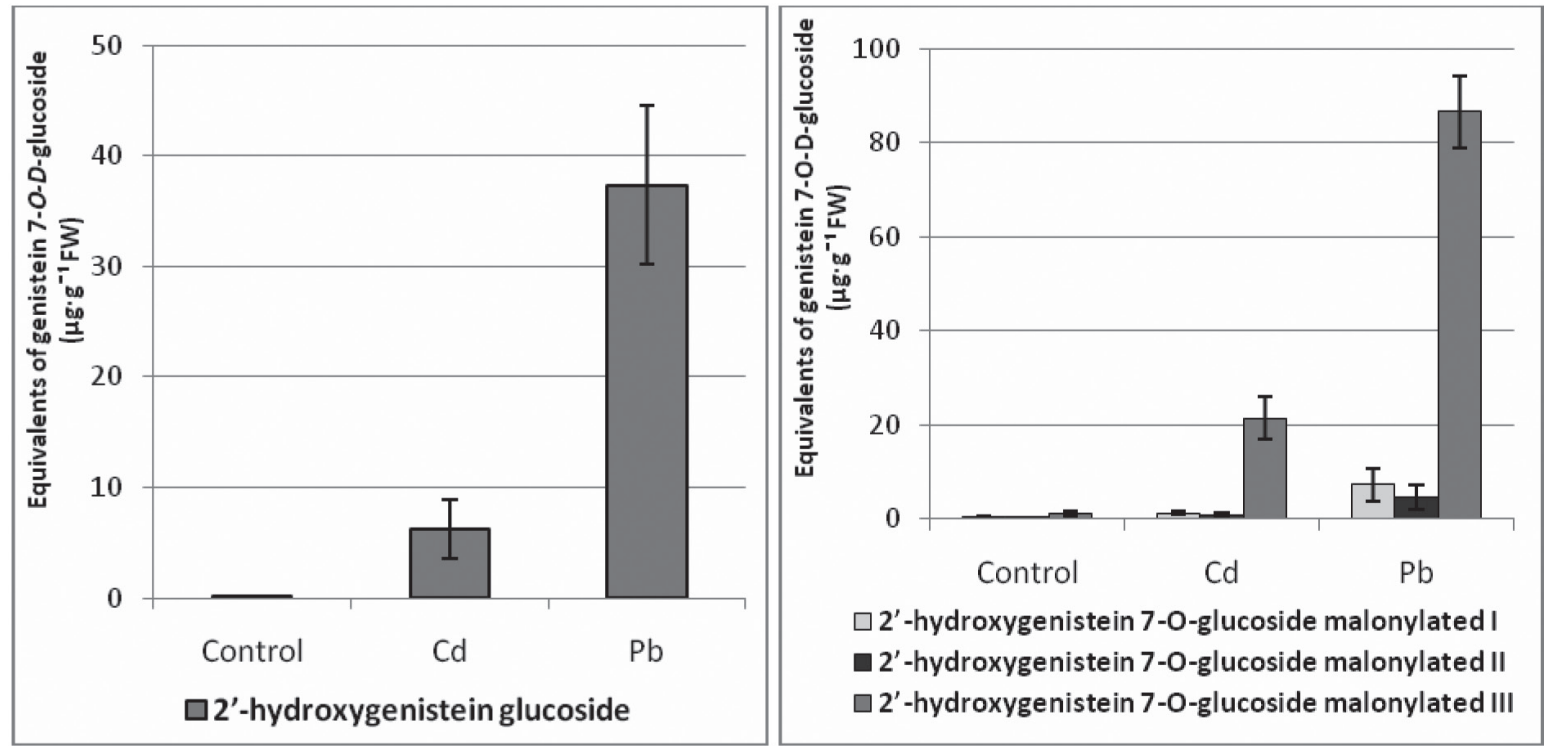

Figure 2. Concentrations of 2'-hydroxygenistein glucoside (a) and 2'-hydroxygenistein 7-O-glucoside malonylated (b) in L. luteus roots treated with $\mathrm{Cd}^{2+}$ or $\mathrm{Pb}^{2+}$

Concentrations of metabolites were calculated as equivalents of genistein 7-O-D-glucoside used for preparation of calibration curve. Values are means \pm S.D. of three independent experiments. FW, fresh weight. 
portant in the plant response to heavy metals: hydroxylation and the level of glycosylation. Genistein diglucosides were more strongly induced by heavy metals than the respective monoglucosides. The position of glucose moiety attachment to genistein seems to play a role as well. A stimulatory effect of heavy metals was observed for of 7-O and $8-C$ glucosides of genistein (Fig. $3 \mathrm{a}$ and $3 \mathrm{~b}$ ), whereas the amount of 4'-O glucoside of genistein was actually decreased in the heavy metals-treated plants (Fig. 3c).

Ample data indicate changes of flavonoid composition in plants exposed to various biotic interactions, both pathogenic and symbiotic (Kosslak et al., 1987; Grandmaison \& Ibrahim, 1995; Morkunas et al., 2005; Muth et al., 2009). Stimulation of genistein and its derivatives

a)

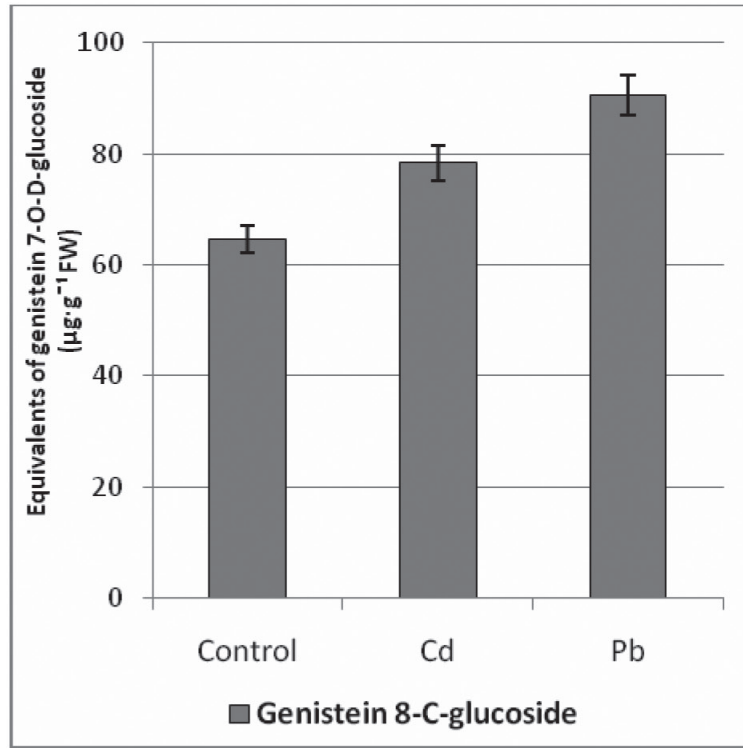

c)

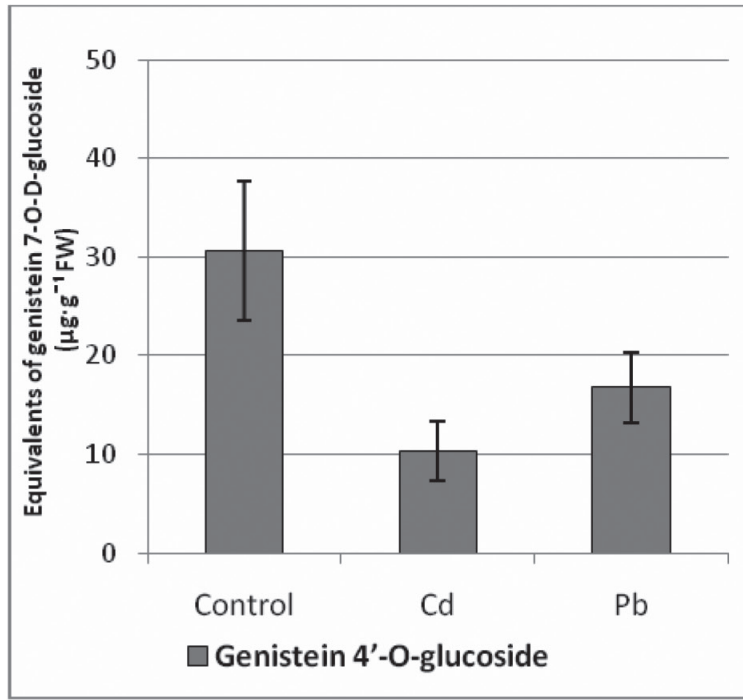

was mostly observed in lupine roots colonized by symbiotic bacteria, whereas prenylated genistein and 2'-hydroxygenistein derivatives (wighteone, luteone) were synthesized during a defense reaction (Bednarek et al., 2003; Luczkiewicz, 2008; Muth et al., 2009). An increase of various flavonoids and isoflavononids has also been documented in different legume plant species in response to infection or elicitation (Treutter, 2005; Naoumkina et al., 2007; Subramanian et al., 2007; Wasson et al., 2009). Increased synthesis of isoflavones was also observed in legumes due to interactions with various abiotic factors, such as light conditions (Bednarek et al., 2003), toxic compounds (potassium cyanide and sodium chloride) (Kneer et al., 1999) as well as heavy metals (Jung et al., 2003; Mithöfer et al., 2004; Michalak, 2006). Treatment of soybean with $\mathrm{Hg}^{2+}$ increased the level of glyceollins

b)

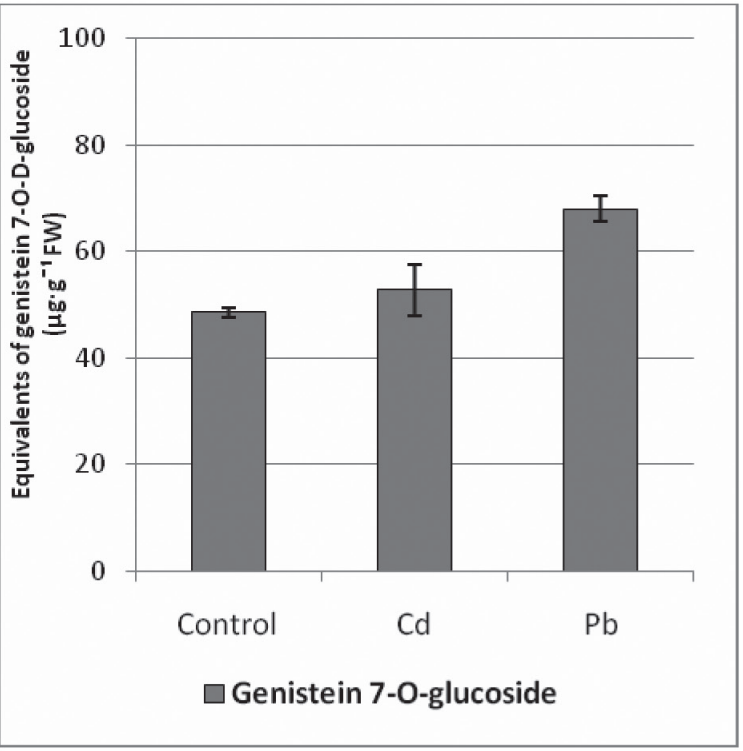

d)

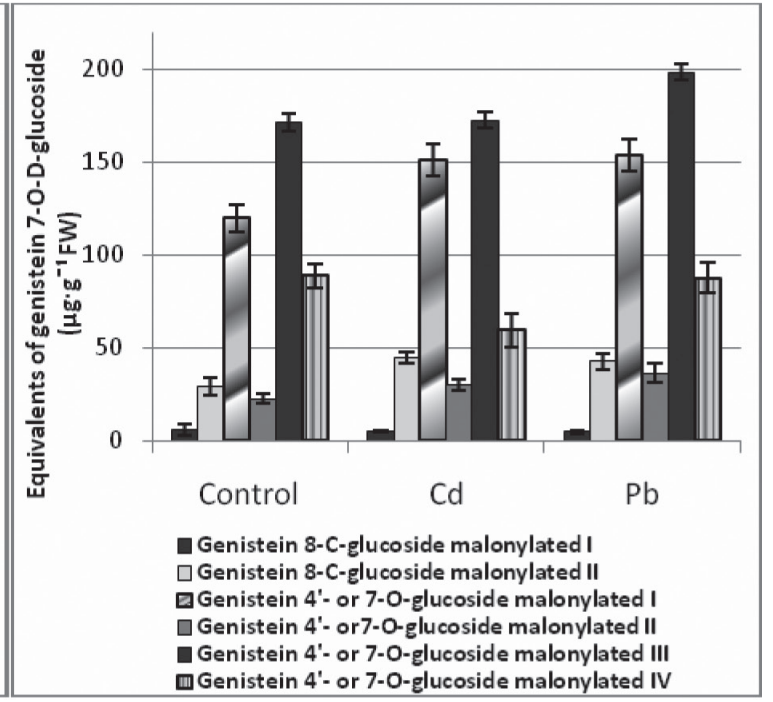

Figure 3. Concentrations of genistein 8-C-glucoside (a), genistein 7-O-glucoside (b), genistein 4'-O-glucoside (c) and genistein 8-Cand 4'- or 7-O-glucoside malonylated (d) in L. luteus roots treated with $\mathrm{Cd}^{2+} \mathrm{or} \mathrm{Pb}^{2+}$

Concentrations of metabolites were calculated as equivalents of genistein 7-O-D-glucoside used for preparation of calibration curve. Values are means \pm S.D. of three independent experiments. FW, fresh weight. 
a)

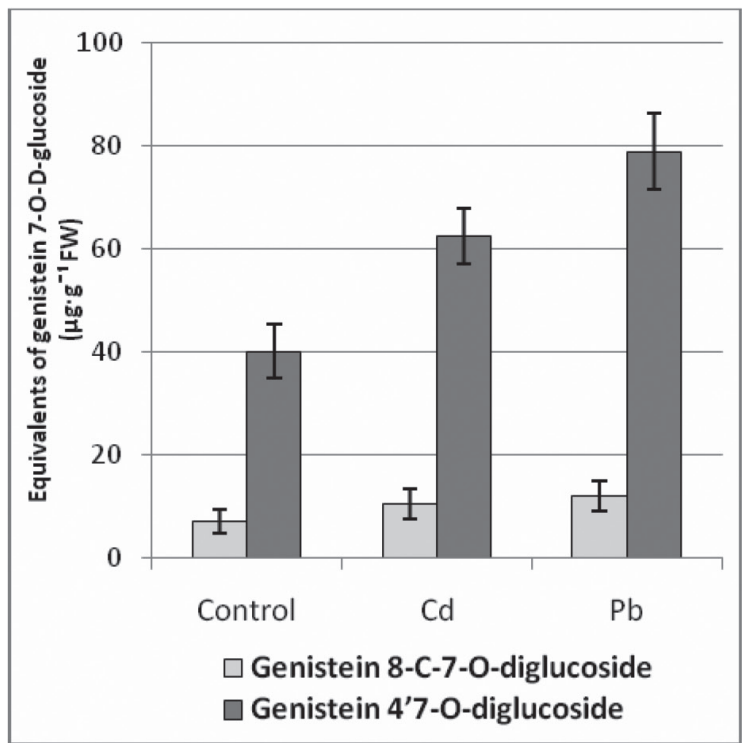

b)

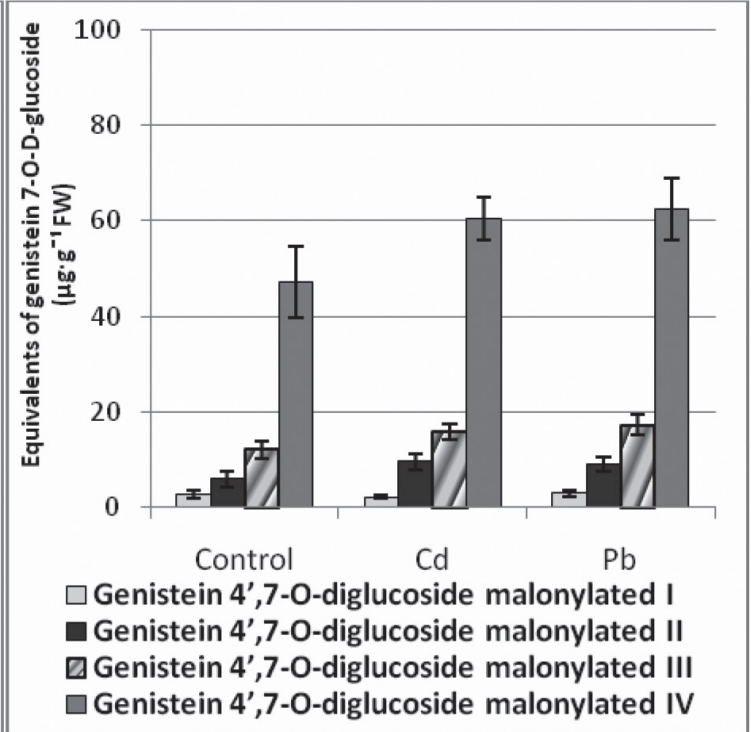

c)

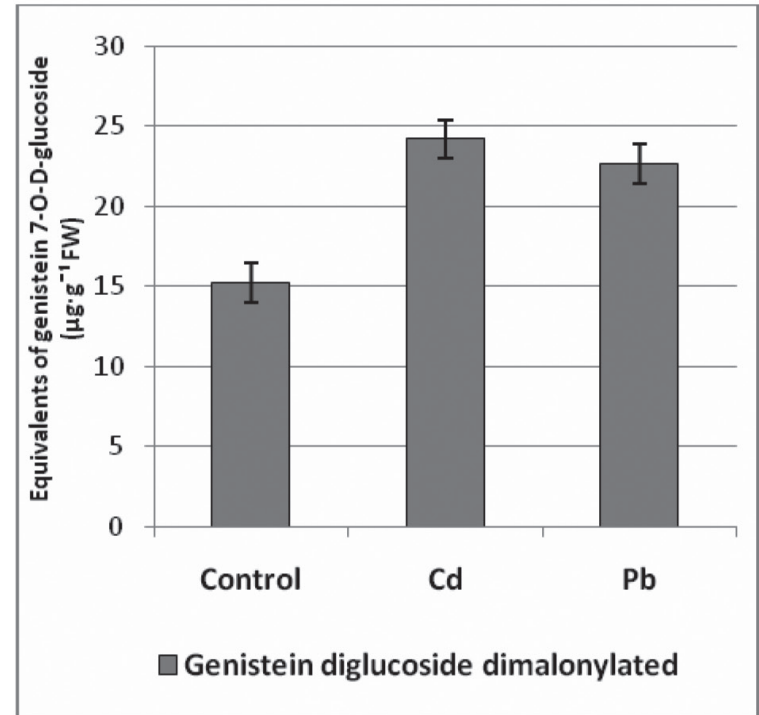

Figure 4. Concentrations of genistein 8-C-7-O- and 4',7-O-diglucoside (a), genistein 4',7-O-diglucoside malonylated (b), genistein diglucoside dimalonylated (c) in L. luteus roots treated with $\mathrm{Cd}^{2+}$ or $\mathrm{Pb}^{2+}$

Concentrations of metabolites were calculated as equivalents of genistein 7-O-D-glucoside used for preparation of calibration curve. Values are means \pm S.D. of three independent experiments. FW, fresh weight.

(Mithöfer et al., 2004), while in $\mathrm{Cu}^{2+}$-treated white lupine (L. albus) cotyledons elevated levels of genistein and 2'-hydroxygenistein were observed (Gagnon \& Ibrahim, 1997; Wojtaszek \& Stobiecki, 1997). Stimulation of genistein synthesis and secretion was also observed in yellow lupine (L. luteus) roots treated with various elicitors, such as soluble chitosan, salicylic acid and potassium cyanide (Kneer et al., 1999). However, the effects of toxic heavy metals, such as cadmium or lead, on isoflavonoid composition in legume plants have not been analyzed so far. Our data indicate that the main compounds which are induced in the root of yellow lupine treated with $\mathrm{Cd}^{2+}$ or $\mathrm{Pb}^{2+}$ are 2 '-hydroxygenistein glucoside and 2'-hydroxygenistein 7-O-glucoside malonylated (Fig. 2a, 2b). We did not observe stimulation of free aglycones of genistein and 2'-hydroxygenistein or their prenylated derivates (wighteone, luteone). It is generally accepted that glycosylation increases the solubility and stability of flavo- noids and isoflavonoids (Modolo et al., 2007). According to Zhao and Dixon (2009) glycosylation is essential for vacuolar uptake whereas malonylation of the sugar group may facilitate transport of the glycoconjugates through membranes. Flavonoids have been suggested to act as antioxidants, protecting cells from oxidative stress (RiceEvans et al., 1996; Winkel-Shirley, 2002; Skórzyńska-Polit et al., 2004; Michalak, 2006; Keiling \& Ludwig-Müller, 2009). Heavy metals increase the level of reactive oxygen species (ROS) which can inflict a serious damage on plant cells (Rucińska et al., 1999; Moller et al., 2007; Sharma \& Dietz, 2009). The ability of flavonoids to chelate metal ions appears to contribute to their antioxidant activity in vitro (Cheng \& Breen, 2000; Mira et al., 2002). It has been documented that a flavonoid complex with a transition metal $\left(\mathrm{Fe}^{3+}, \mathrm{Fe}^{2+}, \mathrm{Cu}^{2+}\right)$ exhibits a superoxide dismutase activity (Kostyuk et al., 2004; 2007). However, the antioxidant function claimed for flavonoids in plants 
is still a matter of debate (Hernandez et al., 2009). The data presented here may suggest additional functions played by isoflavonoid glycoconjugates in plants exposed to heavy metals. The reaction of yellow lupine root cells to $\mathrm{Cd}^{2+}$ and $\mathrm{Pb}^{2+}$ involves an increase of glycosylated and malonyladed forms of the isoflavonoid 2'-hydroxygenistein (Fig. 2a and 2b). Such forms of isoflavonoids may be responsible not only for binding of metal ions, but also for deposition and maintaining of isoflavonoidmetal complexes within the vacuole. Glycosylation and malonylation of flavonoids has recently been attributed to their targeting to the vacuoles (Zhao \& Dixon, 2009).

Based on the obtained data we can also explain the decrease in lignin content in heavy metal-treated roots of yellow lupine (Pawlak-Sprada et al., 2011). It was shown that genistein from $L$. albus is a potent inhibitor of the peroxidase-catalyzed oxidation of coniferyl alcohol, the first step in lignin biosynthesis (Ferrer \& Barcelo, 1994). A similar inhibitory effect on lignin synthesis can be assumed for by 2'-hydroxygenistein glucoside and 2'-hydroxygenistein 7-O-glucoside malonylated, which are strongly stimulated in Lupinus luteus roots treated with $\mathrm{Cd}^{2+}$ or $\mathrm{Pb}^{2+}$.

Although many facts concerning the participation of flavonoids in plant stress response are known the exact function of these metabolites in the plant reaction to toxic heavy metals is still a matter of debate.

\section{Acknowledgements}

This study was partially supported by Ministry of Science and Higher Education (grant N304 077635).

\section{REFERENCES}

Bednarek P, Kerhoas L, Einhorn J, Frański R, Wojtaszek P, RybusZajac M, Stobiecki M (2003) Profiling of flavonoid conjugates in Lupinus albus and Lupinus angusitfolius responding to biotic and abiotic stimuli. J Chem Ecol 29: 1127-1142.

Cheng IF, Breen K (2000) On the ability of four flavonoids, baicilein, luteolin, naringenin, and quercetin, to suppress the Fenton reaction of the iron-ATP complex. Biometals 13: 77-83.

Diaz J, Bernal A, Pomar F, Merino F (2001) Induction of shikimate dehydrogenase and peroxidase in pepper (Capsicum annuиm L.) seedling in response to copper stress and its relation to lignification. Plant Science 161: 179-188.

Dixon RA, Paiva NL (1995) Stress-induced phenylpropanoid metabolism. Plant Cell 7: 1085-1097.

Dixon RA, Achnine L, Kota P, Liu Ch-J, Reddy MSS, Wang L (2002) The phenylpropanoid pathway and plant defence - a genomics perspective. Mol Plant Pathol 3: 371-390.

Ferrer MA, Barceló AR (1994) Control of the lignification in Lupinus by genistein acting as superoxide scavenger and inhibitor of the peroxidase-catalyzed oxidation of coniferyl alcohol. I Plant Physiol 144: 64-67.

Fossen T, Andersen ØM (2006) Spectroscopic techniques applied to flavonoids. In Flavonoids: Chemistry, Biochemistry and Applications. Andersen ØM, Markham KR eds, pp 37-142. CRC Press: Boca Raton.

Gagnon H, Ibrahim RK (1997) Effects of various elicitors on the accumulation and secretion of isoflavonoids in white lupin. Phytochemistry 44: 1463-1467.

Grandmaison J, Ibrahim R (1995) Ultrastructural localization of diprenylated isoflavone in Rhizobium lupine-Lupinus albus symbiotic association. I Exp Bot 46: 231-237.

Hernandez I, Alegre L, Van Breusegen F, Munne-Bosch S (2009) How relevant are flavonoids as antioxidants in plants? Curr Opin Plant Sci 14: $125-132$.

Jouili H, Ferjani EE (2003) Changes in antioxidative and lignifying enzyme activities in sunflower roots (Heliantthus annus L.) stressed with copper excess. CR Biologies 326: 639-644.

Jung Ch, Maeder V, Funk F, Frey B, Sticher H, Frossard E (2003) Release of phenols from Lupinus albus $\mathrm{L}$. roots exposed to $\mathrm{Cu}$ and their possible role in Cu detoxification. Plant Soil 252: 301-312.

Kachlicki P, Marczak L, Kerhosa L, Einhorn J, Stobiecki M (2005) Profiling isoflavone conjugates in root extracts of lupine species with LC/ESI/MS ns systems. J Mass Spectrom 40: 1088-1103.
Kachlicki P, Einhorn J, Muth D, Kerhoas L, Stobiecki M (2008) Evaluation of glycosylation and malonylation patterns in flavonoid glycosides during LC/MS/MS metabolite profiling. I Mass Spectrom 43: 572-586.

Keilig K, Ludwig-Müller J (2009) Effect of flavonoids on heavy metal tolerance in Arabidopsis thaliana seedlings. Botanical Studies 50: 311318.

Kneer R, Poulev AA, Olesinski A, Raskin I (1999) Characterization of the elicitor-induced biosynthesis and secretion of genistein from roots of Lupinus luteus L. J Exp Bot 50: 1553-1559.

Kosslak R, Bookland R, Barkei J, Paaren H, Appelbaum E (1987) Induction of Bradyrbizobium japonicum common nod genes by isoflavones isolated from Glycine max. Proc Nat Acad Sci USA 84: 74287432.

Kostyuk VA, Potapovich AI, Strigunova EN, Kostyuk TV, Afanas'ev IB (2004) Experimental evidence that flavonoid metal complexes may act as mimics of superoxide dismutase. Arch Biochem Biophys 428: 204-208.

Kostyuk VA, Potapovich AI, Kostyuk TV, Cherian MG (2007) Metal complexes of dietary flavonoids: evaluation of radical scavenger properties and protective activity against oxidative stress in vivo. Cell Mol Biol 53: 61-68.

Kovacik J, Klejdus B (2008) Dynamics of phenolic acids and lignin accumulation in metal-treated Matricardia chamomilla roots. Plant Cell Rep 27: 605-615.

Lin Ch-Ch, Chen L-M, Liu Z-H (2005) Rapid effect of copper on lignin biosynthesis in soybean roots. Plant Sci 168: 855-861.

Luczkiewicz MT (2008) Research into isoflavonoid phyto-oestrgens in plant cultures. In Bioactive molecules and medicinal plants. Ramawat KG, Merillon JM eds, pp 55-84. Springer Berlin, Heidelberg.

Michalak A (2006) Phenolic compounds and their antioxidant activity in plants growing under heavy metal stress. Polish J Environ Stud 15: 523-530.

Mira L, Fernandez MT, Santos M, Rocha R, Florencio MH, Jennings KR (2002) Interactions of flavonoids with iron and copper ions: a mechanism for their antioxidant activity. Free Radic Res 36: 1199_ 1208.

Mithöfer A, Schulze B, Boland W (2004) Biotic and heavy metal stress response in plants: evidence for common signals. FEBS Lett 566: $1-5$.

Modolo LV, Blount JW, Achnine L, Naoumkina MA, Wang X, Dixon RA (2007) A functional genomics approach to (iso)flavanoid glycosylation in the model legume Medicago tranculata. Plant Mol Biol 64: 499-518.

Moller IM, Jensen PE, Hansson A (2007) Oxidative modification of cellular components in plants. Annu Rev Plant Biol 58: 459-481.

Morkunas I, Marczak L, Stachowiak J, Stobiecki M (2005) Sucrose induced lupine defense against Fusarium oxysporum. Sucrose-stimulated accumulation of isoflavonoids as a defense response of lupine to Fusarium oxysporum. Plant Physiol Biochem 43: 363-373.

Muth D, Marsden-Edwards E, Kachlicki P, Stobiecki M (2008) Differentiation of isomeric malonylated flavonoid glyconjugates in plant extracts with UPLC-ESI/MS/MS. Phytochem Anal 19: 444-452.

Muth D, Kachlicki P, Krajewski P, Przystalski M, Stobiecki M (2009) Differential metabolic response of narrow leafed lupine (Lupinus angustifolius) leaves to infection with Colletotrichum lupine. Metabolomics 5: $354-362$.

Naoumkina M, Farag MA, Sumner LW, Tang Y, Liu Ch-J, Dixon RA (2007) Different mechanisms for phytoalexin induction by pathogen and wound signals in Medicago truncatula. Proc Natl Acad Sci USA 104: 17909-17915.

Pawlak-Sprada S, Arasimowicz-Jelonek M, Podgórska M, Deckert J (2011) Activation of phenylpropanoid pathway in legume plants expose to heavy metals: Part I. Effects of cadmium and lead on phenylalanine ammonia-lyase gene expression, enzyme activity and lignin content. Acta Biochim Pol 58: 211-216.

Rice-Evans CA, Miller NJ, Paganga G (1996) Structure-antioxidant activity relationships of flavonoids and phenolic acids. Free Radic Biol Med 20: 933-956.

Rucińska R, Waplak S, Gwóźdź EA (1999) Free radical formation and activity of antioxidant enzymes in lupine roots exposed to lead. Plant Physiol Biochem 37: 187-194.

Sharma SS, Dietz K-J (2009) The relationships between metal toxicity and cellular redox imbalance. Trends Plant Sci 14: 43-50.

Skórzynska-Polit E, Drazkiewicz M, Wianowska D, Maksymiec W, Dawidowicz AL, Tukiendorf A (2004) The influence of heavy metal stress on the level of some flavonols in the primary leaves of Phaseolus coccineus. Acta Physiol Plant 26: 247-253.

Stobiecki M, Kachlicki P (2006). Isolation and identification of flavonoids. In: The Science of Flavonoids. Grotewold E ed, 2nd edn, pp 47-69. Springer Science and Business Media, New York.

Stobiecki M, Wojtaszek P, Gulewicz K. (1997) Application of solid phase extraction for profiling of quinolizidine alkaloids and phenolic compounds in lupin tissue. Phytochem Anal 8: 153-158.

Subramanian S, Stacy G, Yu O (2007) Discint, crucial roles of flavonoids during legume nodulation. Trends Plant Sci 12: 282-285. 
Taiz L, Zeiger E (2006) Plant Pbysiology. 4th edn, pp 315-341. Sinauer Associates, Inc. Publisher, Sunderland, Massachusetts, USA.

Treutter D (2005) Significance of flavonoids in plant resistance and enhancement of their biosynthesis. Plant Biol 7: 581-591.

Wasson AP, Ramsay K, Jones MGK, Mathesius U (2009) Differing requirements for flavonoids during the formation of lateral roots, nodules and root knot nematode galls in Medicago truncatula. New Phytol 183: 167-179.

Winkel-Shirley B (2002) Biosynthesis of flavonoids and effects of stress. Curr Opin Plant Biol 5: 218-223.
Wojtaszek P, Stobiecki M (1997) Differential secretion and accumulation of isoflavonoids in Lupinus albus in response to fungal elicitor and $\mathrm{CuCl}_{2}$. Plant Physiol Biochem 35: 129-135.

Yang Y-J, Cheng L-M, Liu Z-H (2007) Rapid effect of cadmium on lignin biosynthesis in soybean roots. Plant Sci 172: 632-637.

Zhao J, Dixon RA (2009) The 'ins' and 'outs' of flavonoid transport. Trends Plant Sci 15: 72-80. 